\title{
Effect of the viscosity ratio on the PLA/PA10.10 bioblends morphology and mechanical properties
}

\author{
J. Cailloux ${ }^{1}$, T. Abt ${ }^{1}$, V. García-Masabet ${ }^{1}$, O. Santana $^{1}$, M. Sánchez-Soto ${ }^{1}$, F. Carrasco ${ }^{2}$, \\ M. Ll. Maspoch ${ }^{1}$
}

${ }^{1}$ Centre Català del Plàstic, Universitat Politécnica de Catalunya Barcelona Tech (UPC-EEBE), C/Colom 114, 08222 Terrassa, Spain

${ }^{2}$ Department of Chemical Engineering, Agriculture and Food Technology, Universitat de Girona (UdG), Campus Montilivi s/n, 17071 Girona, Spain

Received 9 November 2017; accepted in revised form 30 January 2018

\begin{abstract}
PLA bio-blends with a predominantly biosourced PA10.10 in the composition range 10-50 wt $\%$ were prepared by melt blending in order to overcome the advanced brittleness of PLA. Due to the inherent immiscibility of the blends, $30 \mathrm{wt} \%$ of PA was needed to achieve a brittle-to-ductile transition and a co-continuous morphology was predicted at $58 \mathrm{wt} \%$ of PA. The initial enhancement of the PLA rheological behaviour through the environmentally friendly reactive extrusion process yielded a finer and more homogeneous microstructure and hence enhanced the mechanical properties of the bioblends at much lower PA contents. The brittle-to-ductile transition could be achieved with only $10 \mathrm{wt} \%$ and co-continuity was observed already at $44 \mathrm{wt} \%$ of PA. Results indicate the significant potential of modifying PLA flow behaviour as a promising green manufacturing method toward expanding PLA-based bio-blends applications.
\end{abstract}

Keywords: biopolymers, rheology, material testing, mechanical properties

\section{Introduction}

Poly (lactic acid) (PLA) is the front runner in the emerging bio-based and compostable plastic market. Initially, PLA has been viewed as a good alternative to commercial polymers for commodity applications (i.e. packaging). Unfortunately, its advanced brittleness at room temperature $(R T)$ has been its major disadvantage for its implementation into high-value and durable applications (i.e. electronic or automotive).

Blending PLA with other engineering soft polymers represents an industrially relevant strategy for developing bio-based formulations with tailored performances [1]. Specifically, numerous works report the investigation of melt blending PLA with polyamides (PA) [2-7]. However, the inherent immiscibility of this binary polymer system results in rather poor mechanical properties. To overcome the aforementioned issue, Pai et al. [3] as well as Patel et al. [7] reported the first intents to compatibilize PLA/PA blends by adding titanium isopropoxide and a low molecular weight $\left(M_{\mathrm{w}}\right)$ epoxy resin, respectively. Unfortunately, a high PA content ( $\geq 50 \mathrm{wt} \%$ ) is needed to change the blend morphology from droplet-matrix to co-continuous in order to improve the mechanical properties $[4,6,7]$. Therefore, PLA/PA blends with a predominant PLA content still exhibit brittleness.

Polymer blends exhibiting a fine-tuned morphology with a significant reduced droplet size of the minor phase are promising due to their enhanced toughness in comparison to coarse sea-island morphologies [8]. Nuzzo et al. [6] reported the use of a third component (i.e. nanoparticles) in PLA/PA11 blends to both

$\overline{{ }^{*} \text { Corresponding author, e-mail: jonathan.cailloux@upc.edu }}$ C BME-PT 
decrease the droplet size of the PA dispersed phase and to shift the onset of co-continuity towards lower PA amounts (30 wt\%). However, mechanical properties are still far from being enhanced. In the case of selective positioning at the polymer-polymer interface, nanofillers act as stress concentrators; thus weakening the interfacial adhesion [6]. Moreover, the addition of nanoparticles is relatively complicated for large-scale productions. Hence, an on-line processing technique that offers control over both the minor phase size and morphology is a desirable alternative to tailor the mechanical properties of PLA/PA blends.

Among all available strategies enabling a processcontrolled morphogenesis, the viscosity ratio of the blend, $\lambda$, i.e. the viscosity of the minor phase $\left(\eta_{\text {minor }}\right)$ divided by that of the matrix phase $\left(\eta_{\text {major }}\right)$ (in this case $\lambda=\eta_{\text {PA }} / \eta_{\text {PLA }}$ ), plays a major role in the final blend morphology [9-11]. Despite the general agreement in recognizing that usually $\eta_{\mathrm{PA}} / \eta_{\mathrm{PLA}}>1$ [4], investigations relating the role of modifying the PLA rheological behaviour on the final PLA/PA blend morphologies remain unavailable, to the best of the authors' knowledge. The present work addresses these issues through a comparative study of bioblends of a rheologically modified PLA (referred to as PLA $A_{R E x}$ ) and a green bio-based PA10.10. This commercially available PA grade was chosen because of its relatively low melting temperature; thus minimizing the well-known thermal degradations of PLA during processing [12]. Moreover, its green biobased character highlights a research effort on the development of entirely bio-sourced blends to make the material suitable for a wider range of products.

Specifically, reactive extrusion using a multifunctional epoxide reactive agent (referred to as SAmfE) was used to enhance the PLA flow behaviour in a pilot plant. Then, the effect of this tailored viscosity ratio on both the morphology and mechanical behaviour of these PLA $\mathrm{REx}_{\mathrm{RA}} / \mathrm{PA}$ bio-blends were investigated and compared to unmodified PLA/PA bio-blends.

\section{Experimental}

\subsection{Materials}

A commercially available extrusion-grade PLA (Ingeo $4032 \mathrm{D}^{\circledR}$; D lactide content: $2 \%$ ) was purchased from Natureworks (Arendonk, Belgium) and used as received. SAmfE reactive agent, namely Joncryl-ADR-4300 ${ }^{\circledR}$, was kindly supplied by BASF (Ludwigshafen, Germany) with an epoxy equivalent weight of $433 \mathrm{~g} \cdot \mathrm{mol}^{-1}$ and a functionality of about 12. The predominantly bio-based PA 10.10 was produced by Dupont (Midland, USA) under the trade name Zytel RS LC1000 BK385.

\subsection{Reactive extrusion and sample preparation}

The bio-blends were prepared using a two-step process. Prior to processing, raw PLA was dried at $80^{\circ} \mathrm{C}$ for $4 \mathrm{~h}$ in a Piovan (DSN506HE, Venice, Italy) hopper-dryer (dew point $\left.=-40^{\circ} \mathrm{C}\right)$. SAmfE flakes were vacuum-dried overnight at RT over silica gel. Initially, the enhancement of the PLA melt properties was achieved through reactive extrusion using a corotating twin-screw extruder with a screw diameter of $25 \mathrm{~mm}(L / D=36)$ (KNETER 25X24D, Collin $\mathrm{GmbH}$, Ebersberg, Germany) and a nominal SAmfE content of $0.6 \mathrm{wt} \%$. The seven heating zones were set to $45,165,165,170,180,190,190^{\circ} \mathrm{C}$ from the feeding zone to the die, respectively. The screw speed was set to $35 \mathrm{rpm}$; leading to a residence time of $4.1 \mathrm{~min}$. A $\mathrm{N}_{2}$ blanket was introduced in the hopper of the feeding zone and vacuum was applied to the metering zone. The extrudate (referred to as PLAREx) was water-cooled and pelletized.

Then, five PLA $\mathrm{REx}_{\mathrm{PA}}$ blends, covering the 10$50 \mathrm{wt} \%$ PA composition range, were prepared by melt mixing using a Brabender batch mixer (Brabender Plastic-Corder W50EHT, Brabender GmbH\&Co., Duisburg, Germany) operated at $210^{\circ} \mathrm{C}$ and $50 \mathrm{rpm}$ for 12 min under a $\mathrm{N}_{2}$ blanket. The obtained materials

Table 1. Formulation and nomenclature of all investigated samples.

\begin{tabular}{|c|c|c|}
\hline $\begin{array}{c}\text { Sample } \\
\text { nomenclature }\end{array}$ & $\begin{array}{l}\text { PLA/PA } \\
{[w t / w t]}\end{array}$ & $\begin{array}{c}\text { PLA }_{\text {REx }} / \mathbf{P A} \\
{[w t / w t]}\end{array}$ \\
\hline PLA & $100 / 0$ & - \\
\hline PLAREx $_{\text {RL }}$ & - & $100 / 0$ \\
\hline PA & $0 / 100$ & - \\
\hline \multicolumn{3}{|c|}{ PLA-based bio-blends } \\
\hline PLA90 & $90 / 10$ & - \\
\hline PLA80 & $80 / 20$ & - \\
\hline PLA70 & $70 / 30$ & - \\
\hline PLA60 & $60 / 40$ & - \\
\hline PLA50 & $50 / 50$ & - \\
\hline \multicolumn{3}{|c|}{ PLA $A_{\text {REx }}$-based bio-blends } \\
\hline $\mathrm{PLA}_{\mathrm{REx}} 90$ & - & $90 / 10$ \\
\hline $\mathrm{PLA}_{\mathrm{REx}} 80$ & - & $80 / 20$ \\
\hline $\mathrm{PLA}_{\mathrm{REx}} 70$ & - & $70 / 30$ \\
\hline $\mathrm{PLA}_{\mathrm{REx}} 60$ & - & $60 / 40$ \\
\hline $\mathrm{PLA}_{\mathrm{REx}} 50$ & - & $50 / 50$ \\
\hline
\end{tabular}


were further compression moulded into $0.6 \mathrm{~mm}$ thick plates in an IQAP LAP PL-15 hot plate press (IQAP Masterbatch SL, Barcelona, Spain) for $5 \mathrm{~min}$ at $210^{\circ} \mathrm{C}$ and $4 \mathrm{MPa}$ and then cooled to RT at about $-50^{\circ} \mathrm{C} / \mathrm{min}$. Prior to processing, PLA $\mathrm{REx}_{\mathrm{x}}$ and PA were vacuum-dried overnight at $80^{\circ} \mathrm{C}$ over silica gel. For the sake of comparison, five PLA/PA blends as well as the three pure polymers (i.e. PLA, PLA REx $_{1}$, PA) were also manufactured using the same processing conditions. All prepared samples are summarized in Table 1.

\subsection{Dynamic rheological measurements}

The raw materials (i.e. PLA, PLA ${ }_{\text {REx }}$, PA pellets) were rheologically characterized using an AR-G2 rheometer (TA Instruments, New Castle, DE, USA) under dry $\mathrm{N}_{2}$ atmosphere in parallel plate (diameter $=25 \mathrm{~mm}$ ) configuration with a constant gap of $1 \mathrm{~mm}$. Prior to testing, pellets were vacuum-dried overnight at $55^{\circ} \mathrm{C}$ over silica gel. Measurements were performed at small strains to ensure that the material's response was in the linear viscoelastic regime (LVR). Dynamic frequency sweeps were carried out at $210^{\circ} \mathrm{C}$ (i.e. blend processing temperature), in the frequency $(\omega)$ range $0.0628<\omega<628 \mathrm{rad} \cdot \mathrm{s}^{-1}$ under controlled deformation conditions ( $2 \%$, LVR).

\subsection{Size-exclusion chromatography (SEC)}

The molecular weight distribution of the raw materials was determined at RT using an Agilent model Infinity 1260 SEC system (Agilent Technologies, Santa Clara, CA, USA) equipped with an Agilent PL HFIPgel $(300 \times 7.5 \mathrm{~mm})$ specialist column (flow rate: $\left.1 \mathrm{~mL} \cdot \mathrm{min}^{-1}\right)$ and a differential refractive index detection (SEC-DRI). Hexafluoroisopropanol (HFIP) containing $0.02 \mathrm{~mol} \cdot \mathrm{L}^{-1}$ of sodium trifluoroacetate to prevent polyelectrolyte effect was used as eluent. Molar mass values $\left(M_{\mathrm{n}}\right.$ and $M_{\mathrm{w}}$ being the number and weight average MW, respectively) were calculated by reference to a relative calibration curve obtained with poly(metyl methacrylate) standards.

\subsection{Scanning electron microscopy (SEM)}

The surface morphology observation was performed on cryogenically fractured samples, on surface etched samples and tensile fractured surfaces using a JSM$7001 \mathrm{~F}$ scanning electron microscope (JEOL, Tokyo, Japan) operated at $2 \mathrm{kV}$. Prior to SEM analysis all samples were sputter coated with a thin platinumpalladium (80:20) layer.

\subsection{Selective surface etching and image analysis}

According to the methodology proposed by Kakroodi et al. [2], the etching procedure performed on the cryogenically fractured surfaces was as follows. Samples were etched in a water-methanol solution (1:2 vol./vol.) containing $0.025 \mathrm{~mol} \cdot \mathrm{L}^{-1}$ of sodium hydroxide for 7 days at RT, rinsed with distilled water and then dried at $23{ }^{\circ} \mathrm{C}$ for 2 days before SEM observations. An open-source software (ImageJ version $1.51 \mathrm{p})$ was used for image analysis. The weight-average particle diameter $\bar{d}_{\mathrm{w}}$ was determined from a representative surface area of $108 \mu \mathrm{m}^{2}$ according to Equation (1):

$\bar{d}_{\mathrm{w}}=\frac{\sum n_{\mathrm{i}} d_{\mathrm{i}}^{2}}{\sum n_{\mathrm{i}} d_{\mathrm{i}}}$

where $n$ is the number of particles having diameter $d$.

\subsection{Wide-angle $X$-ray scattering (WAXS)}

WAXS measurements were carried out on a Bruker D8 Advance diffractometer (Billerica, MA, USA) with $\mathrm{CuK} \alpha$ radiation of wavelength of $1.54 \AA$. $2 \mathrm{D}$ WAXS patterns were recorded in the range $5-35^{\circ}$ (step size $=0.02$, scanning speed $=1 \mathrm{~s} /$ step) using a PSD LynxEye detector at room temperature.

\subsection{Contact angle measurements and surface free energy calculation}

The contact angles of distilled water (polar liquid) and diiodomethane (dispersion liquid) were measured by an optical contact angle measuring and contour analysis system (DataPhysics Instruments $\mathrm{GmbH}$, Filderstadt, Germany) using the sessile drop method. The static drops had a volume of $3 \mu \mathrm{L}$. At least 8 measurements were done for each sample at a temperature of $22 \pm 1^{\circ} \mathrm{C}$. The surface free energy of PLA, $\mathrm{PLA}_{\mathrm{REx}}$ and PA and their polar and dispersive components were determined according to Equation (2) using the Owens-Wendt method $[13,14]$ :

$\gamma_{1}(1+\cos (\theta))=2 \sqrt{\gamma_{s}^{\mathrm{d}} \gamma_{1}^{\mathrm{d}}}+2 \sqrt{\gamma_{\mathrm{s}}^{\mathrm{p}} \gamma_{1}^{\mathrm{p}}}$

where $\gamma_{1}$ is the surface tension of the liquid, $\theta$ is the contact angle and $\gamma_{\mathrm{s}}$ is the surface tension of the solid, also referred to as surface free energy. Superscripts ' $d$ ' and ' $p$ ' denote the dispersive and polar component of the surface free energy. Water: $\gamma_{1}^{\mathrm{d}}=21.8 \mathrm{~mJ} / \mathrm{m}^{2}, \gamma_{1}^{\mathrm{p}}=51 \mathrm{~mJ} / \mathrm{m}^{2}$; diiodomethane: $\gamma_{1}^{\mathrm{d}}=48.6 \mathrm{~mJ} / \mathrm{m}^{2}, \gamma_{1}^{\mathrm{p}}=2.2 \mathrm{~mJ} / \mathrm{m}^{2}$ [15]. 


\subsection{Tensile testing}

The mechanical characterization was performed at both low and high strain rates in order to evaluate the tensile and fracture behaviours, respectively. Type 1BA dumbbell specimens according to ISO 527-2 were rapidly extracted from the compression moulded plates after processing in order to avoid excessive defects during punching. Prior to testing, all samples were stored at RT during one week in order to drive the physical aging process closer to equilibrium. All experiments were performed at RT and a relative humidity content of $50 \%$.

The uniaxial tensile behaviour was assessed according to ISO 527 using a Zwick Roell Z010 testing machine (Zwick Roell, Ulm, Germany) equipped with a $10 \mathrm{kN}$ load cell. A minimum of five specimens were tested at a constant crosshead speed of $10 \mathrm{~mm} \cdot \mathrm{min}^{-1}$ whereas the Young's modulus $(E)$ was determined at $1 \mathrm{~mm} \cdot \mathrm{min}^{-1}$. Young's modulus $(E)$, tensile strength $\left(\sigma_{\mathrm{m}}\right)$, strain at the maximum stress $\left(\varepsilon_{\mathrm{m}}\right)$ and strain at break $\left(\varepsilon_{\mathrm{b}}\right)$ were determined from the engineering stress-strain curves.

\subsection{Tensile-impact testing}

The fracture behaviour was evaluated through tensile-impact tests using a Resil Impactor Junior pendulum impact tester (CEAST, Italy) following the ISO 8256 method A. The striker had a reduced mass of $3.65 \mathrm{~kg}$, the impact speed was $1.92 \mathrm{~m} \cdot \mathrm{s}^{-1}$ and the nominal impact energy was $6.75 \mathrm{~J}$. A minimum of 10 unnotched specimens were tested in order to report the tensile-impact strength $\left(\mathrm{a}_{\mathrm{tU}}\right)$.

\section{Results and discussion}

It is well known that the morphology of polymer blends is directly related to the rheological behaviour of their individual components. Therefore, the flow behaviour of the three raw materials was determined in order to predict the composition of the blend where phase inversion occurs. Figure 1 compares the viscosity shear rate dependence for the selected PLA and PA grades to that of PLAREx at $210^{\circ} \mathrm{C}$; i.e. compounding and compression-moulding temperature. The shear viscosity was related to the absolute value of the complex viscosity, determined using dynamic frequency sweeps, assuming the validity of the CoxMerz rule [16].

PLA exhibits the typical behaviour of linear polymers (i.e. typical pseudoplastic fluid behaviour), while the PA shows pronounced shear-thinning flow

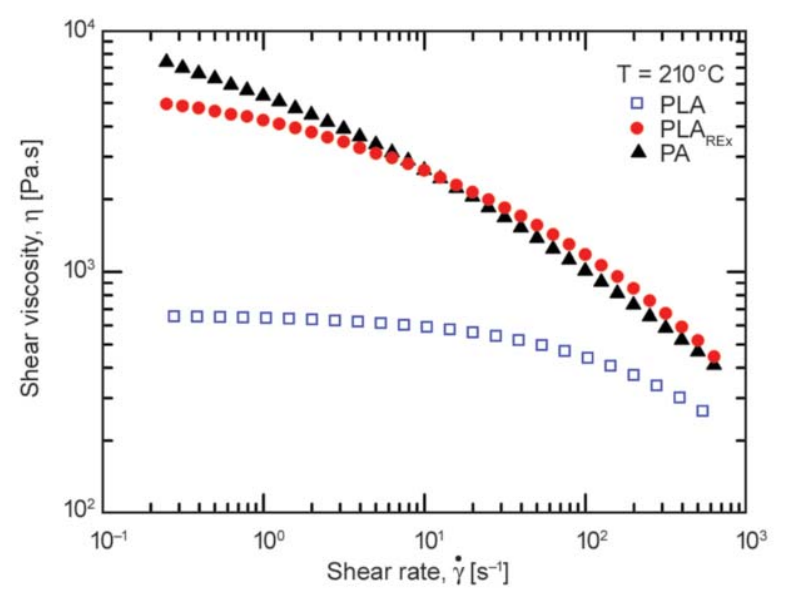

Figure 1. Influence of the reactive processing on the viscosity shear rate dependence of PLA REx.

behaviour. Even though PA exhibits a lower MW than PLA (c.f. Table 2), the PA shear viscosity is considerably higher than that of PLA over the entire range of shear rate investigated. This may be ascribed to the intermolecular interactions between the PA macromolecular chains (i.e. Van der Waals forces between the amide groups), which increase the fluid friction and render PA more viscous than PLA [17]. This behaviour is indicative of a viscosity ratio $\lambda=$ $\eta_{\text {PA }} / \eta_{\text {PLA }}>1$. In other words, PLA/PA blends are likely to form a dispersed morphology having PLA as the continuous phase and PA as the discrete phase (i.e. droplets).

Among the available models to predict the phase inversion composition $\phi_{2, \mathrm{PI}}$, the so-called Paul and Barlow equation is the most commonly used approach [18-20]. The validity of this basic equation which describes $\phi_{2, \text { PI }}$ in terms of volume fractions and viscosities was largely confirmed in several studies for immiscible polymeric blends with $\lambda$ near unity $[21-$ 23]. Nevertheless, large discrepancies between $\phi_{2, \mathrm{PI}}$ predictions and morphological observations were reported for blend systems with significant viscosity differences [21, 24-26]. In the present work, the Utracki model [24] was preferred to predict $\phi_{2, P I}$ since $\lambda=\eta_{\text {PA }} / \eta_{\text {PLA }}>1$. This model has been already successfully used to predict $\phi_{2, \text { PI }}$ for blends with $\lambda$ different from unity [21, 24-26]. This approach is based on the 'intrinsic viscosity' $[\eta]$ and the maximum packing volume fraction $\phi_{\mathrm{m}}$ given by Equation (3):

$\lambda=\left[\frac{\phi_{\mathrm{m}}-\phi_{2, \mathrm{PI}}}{\phi_{\mathrm{m}}-\phi_{1, \mathrm{PI}}}\right]^{|\eta| \phi_{\mathrm{m}}}$

where $\lambda=\eta_{\text {PA }} / \eta_{\text {PLA }}$ at the shear rate used for blend preparation, $\phi_{2, \mathrm{PI}}$ is the volume fraction at the phase 
inversion of the PLA or PLA $\mathrm{REx}_{\text {x }}$ phase, respectively and $\phi_{2, \mathrm{PI}}=1-\phi_{1, \mathrm{PI}}$.

In the range $0.1 \leq \lambda \leq 10$, Equation (3) expanded into the MacLaurin's series and truncated after the second term can be approximated as shown in Equation (4):

$\phi_{2, \mathrm{PI}}=\frac{1-\frac{\log \lambda}{|\eta|}}{2}$

Based on published data of the points of phase inversion of several thermoplastics and rubbers, Utracki reported that the optimum value for [ $\eta]$ is 1.9 [24]. The shear viscosity at approximately $55 \mathrm{~s}^{-1}$ was chosen to calculate $\lambda$ as it was considered representative of the maximum shear rate at a rotor speed of $50 \mathrm{rpm}$ in the Brabender batch mixer employed. Specifically, the maximum shear rate was estimated using the methodology developed by Bousmina et al. [27]. Regarding PLA/PA bio-blends, the estimated value of $\phi_{2, \mathrm{PI}}$ indicates that the composition of phase inversion is about $38 \mathrm{vol} \%$ of PLA (c.f. Table 2). Thus, the theoretical point of phase inversion is reached at a rather low PLA weight fraction $W_{2 \text {,PI }}$ of $42 \mathrm{wt} \%$.

The fundamental challenge is to shift $\phi_{2, \mathrm{PI}}$ towards higher PLA contents in order to manufacture PLA/PA bio-blends with a predominant PLA content. Accordingly, the PLA flow behaviour was modified through reactive extrusion using a multifunctional epoxide. As can be seen in Figure 1, PLA REx $_{\text {exhibits a sig- }}$ nificantly higher shear viscosity over the whole experimental window as compared to PLA. The former equally presents pronounced shear-thinning flow behaviour similar to that of PA. This difference is ascribed to the alteration of the molecular mobility due to the chemical reactions which may take place between the PLA functional end groups and the epoxy ring of the chain extender. Since SAmfE is a multifunctional reactive agent, several PLA chains may be chemically bound to one SAmfE molecule through chain extension or branching reactions, as already reported elsewhere [28]. The complex topological modifications generated coupled with an increasing number of interactions and entanglements per chains (i.e. higher $M_{\mathrm{w}}$, c.f. Table 2) led to a decreasing rate of molecular relaxation, thus enhancing the PLA $A_{\text {REx }}$ flow properties.

PLA $_{\text {REx }}$ exhibited similar $\eta$ values at $55 \mathrm{~s}^{-1}$ as PA, as shown in Figure 1. Therefore, $\lambda$ was significantly reduced for PLA $A_{\mathrm{REx}} / \mathrm{PA}$ bio-blends; thus shifting the theoretical $\phi_{2, \mathrm{PI}}$ to a higher PLA $A_{\mathrm{REx}}$ content of $56 \mathrm{wt} \%$ (c.f. Table 2). Since this current study is focused on bio-blends with a predominant PLA content, five $\mathrm{PLA}_{\mathrm{REx}} / \mathrm{PA}$ blends covering the $10-50 \mathrm{wt} \%$ PA composition range were further investigated (c.f. Table 1). PLA/PA bio-blends were equally processed for the sake of comparison.

Since the final blend properties are highly dependent on the induced morphology, SEM observations were carried out on the cryogenically fractured surface of PLA and PLA $A_{\text {REx }}$-based bio-blends (Figure 2). Regarding PLA-based bio-blends, SEM micrographs revealed the expected two-phase structure independently of the formulation considered. The sea-island morphology in which droplets of the PA phase were embedded in the continuous PLA matrix confirms the basic immiscible nature of the PLA/PA10.10 bioblends. Increasing the PA content apparently seems to induce a growth of the average drop size. As noted on the cryofractured surface, each formulation released the triaxial stress state induced during fracture by voiding and second phase particle debonding. This behaviour indicates a poor interfacial adhesion between both components.

Table 2. Technical specifications for the three raw materials used in this study.

\begin{tabular}{|c|c|c|c|c|c|c|c|}
\hline Material code & $\begin{array}{c}T_{\mathrm{mp}} / \boldsymbol{T}_{\mathrm{me}^{\mathrm{a}}} \\
{\left[{ }^{\circ} \mathrm{C}\right]}\end{array}$ & $\begin{array}{c}M_{\mathrm{n}} / M_{\mathrm{w}}^{\mathrm{b}} \\
{[\mathrm{kDa}]}\end{array}$ & $\begin{array}{c}\text { MFI } \\
\text { at } 210^{\circ} \mathrm{C}, 2.16 \mathrm{~kg} \\
{[\mathrm{~g} / 10 \mathrm{~min}]}\end{array}$ & $\begin{array}{c}\underset{\eta}{\eta} \dot{\gamma}=55 \mathrm{~s}^{-1}, 210^{\circ} \mathrm{C} \\
{[\mathrm{Pa} \cdot \mathrm{s}]}\end{array}$ & at $\begin{array}{c}\lambda^{\mathrm{d}} \\
\dot{\gamma}=55 \mathrm{~s}^{-1}\end{array}$ & $\begin{array}{c}\phi_{2, \mathrm{PI}} \\
{[\mathrm{vol} \%]}\end{array}$ & $\begin{array}{l}W_{2, \mathrm{PI}}{ }^{\mathrm{e}} \\
{[\mathrm{wt} \%]}\end{array}$ \\
\hline PLA & $167 / 173$ & $90 / 181$ & $6.4 \pm 0.3$ & 504 & 2.74 & 38 & 42 \\
\hline $\mathrm{PLA}_{\mathrm{REX}}$ & $165 / 171$ & $121 / 290$ & $1.1 \pm 0.1$ & 1567 & 0.88 & 52 & 56 \\
\hline PA & $200 / 206$ & $11 / 33$ & $-^{\mathrm{c}}$ & 1383 & - & - & - \\
\hline
\end{tabular}

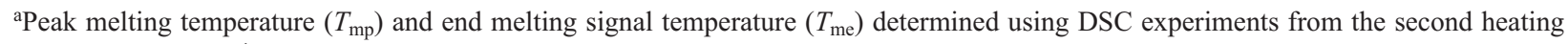
cycle at $10^{\circ} \mathrm{C} \cdot \mathrm{min}^{-1}$.

${ }^{\mathrm{b}}$ Relative values determined using SEC-DRI experiments.

${ }^{\mathrm{c}}$ Not determined for this material.

$\mathrm{d} \lambda=\eta_{\mathrm{PA}} / \eta_{\text {major phase }}$, being PLA or PLA $A_{\mathrm{REx}}$ the major phase for PLA and PLA $A_{\text {REx }}$-based bio-blends, respectively.

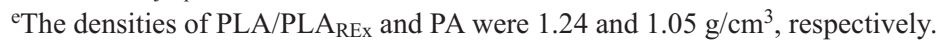



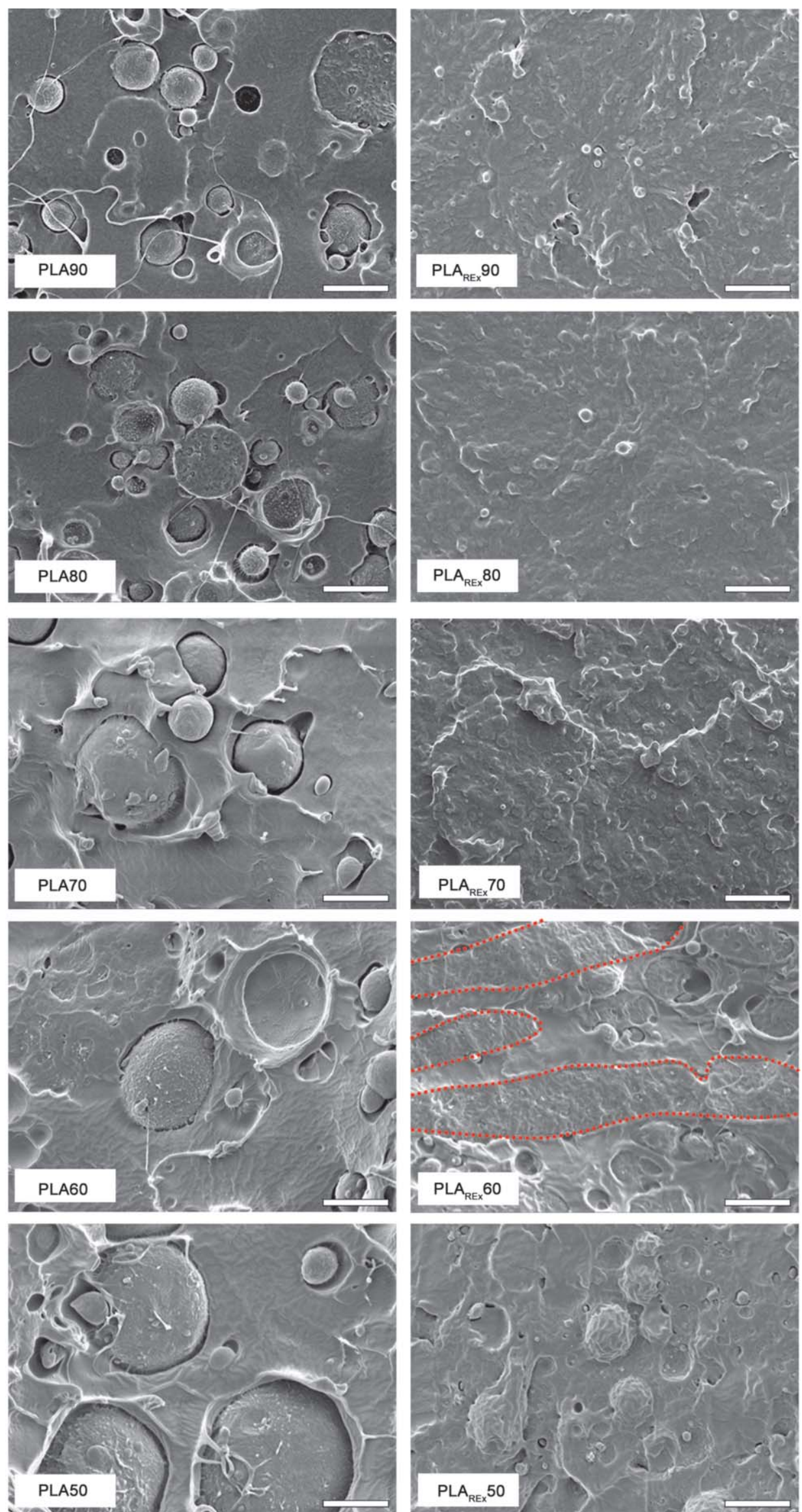

Figure 2. SEM micrographs $(\times 10000)$ of the cryofractured surfaces of PLA and PLA $A_{R E x}$ based bio-blends, respectively. Continuous domains of PA are highlighted within the red dashed lines. Scale bars $=2 \mu \mathrm{m}$. 

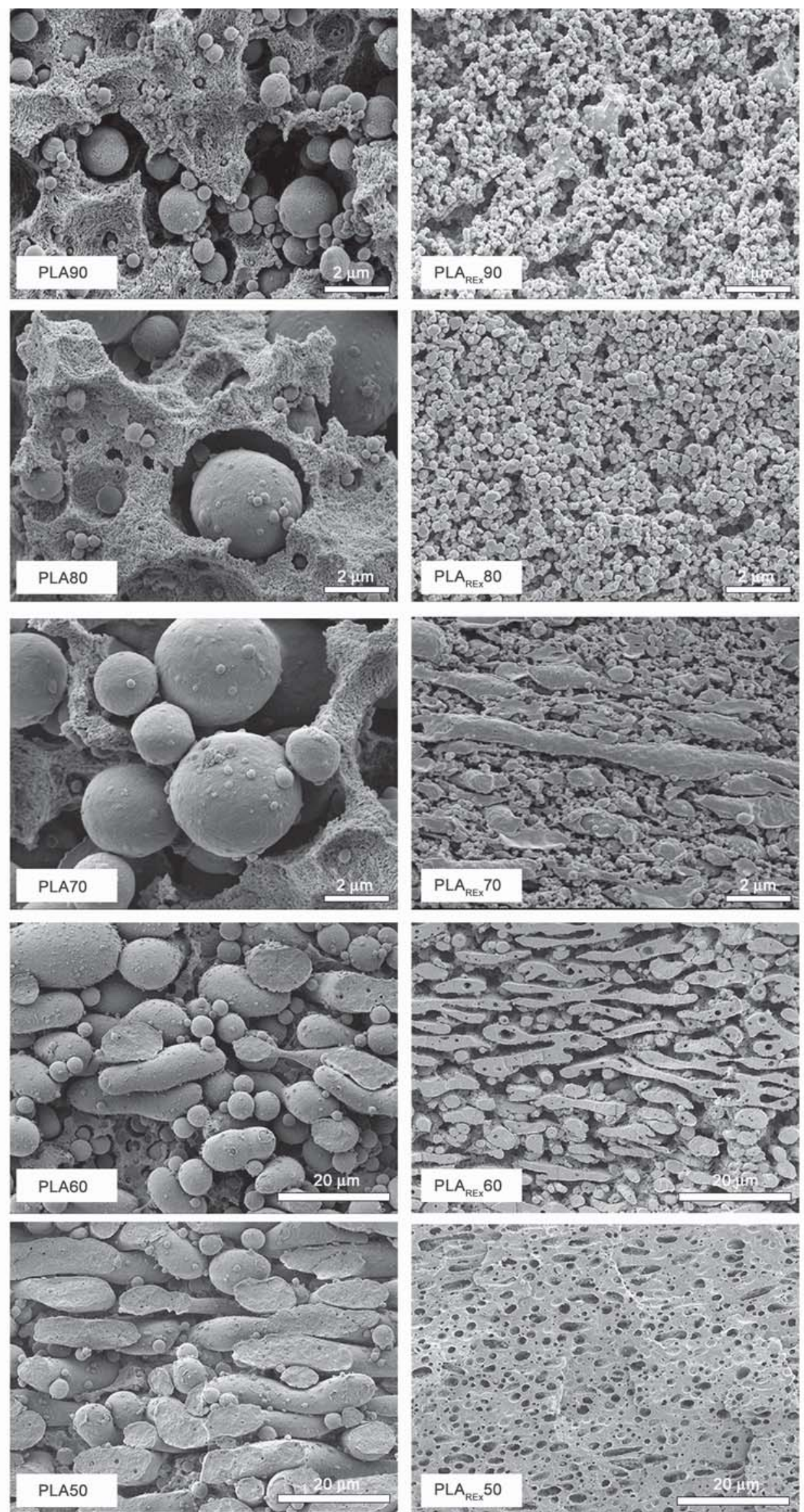

Figure 3. SEM micrographs of the cryofractured surfaces of PLA and PLA $A_{R E x}$ based bio-blends after surface etching. Regarding PA composition in the range $10-30 \mathrm{wt} \%$, scale bars $=2 \mu \mathrm{m}(\times 10000)$. For $60 / 40$ and $50 / 50$ formulations, scale bars $=20 \mu \mathrm{m}(\times 1500)$. 
In contrast, the cryofractured surface morphology of PLA $_{\text {REx }}$-based bio-blends did not display any clear evidence of phase-separated domains. Moreover, the rare and smaller PA drops which were found on the fracture surface of the $\operatorname{PLA}_{\mathrm{REx}} 90, \mathrm{PLA}_{\mathrm{REx}} 80$ and $\mathrm{PLA}_{\mathrm{REx}} 70$ formulations seemed to be covered with matrix. This observation suggests a better interfacial adhesion between both polymers. When the PA content increased up to $40 \mathrm{wt} \%$ continuous domains of PA appeared (indicated within the red dashed lines in Figure 2), suggesting that this formulation was at the onset of co-continuity. Nevertheless, the analysis of $\mathrm{PLA}_{\mathrm{REX}} / \mathrm{PA}$ SEM micrographs suffered from the intrinsic two-dimensional feature of the image coupled with the poor separation between both polymers. Thus, possibility of misinterpreting the blend morphology is largely expected. To substantiate the previous observations, surface etching of the PLA $\mathrm{AEx}_{\mathrm{RE}}$ matrix was performed to provide an insight into the PA morphology in PLA $\mathrm{REx}_{\mathrm{PA}} / \mathrm{P}$ bio-blends. For comparison purposes, PLA/PA bio-blends were equally surface etched using the same conditions.

Figure 3 shows the dispersion of the remaining PA phase after the PLA and PLAREx selective surface etching, respectively. Regarding PLA-based bioblends in the composition range of $90-70 \mathrm{wt} \%$, it can be seen that the PLA matrix remained visible in the corresponding micrographs of the etched surfaces. This observation suggests that the near-spherical PA droplets were non-uniformly suspended in the PLA matrix and were not self-supported during the etching process. As can be seen in Table 4, increasing the PA content from 10 to $30 \mathrm{wt} \%$ significantly increased the weight-average particle diameter from initially 0,7 to $2,6 \mu \mathrm{m}$. The etched surface of the PLA60 formulation shows the coexistence of spherical PA droplets with some coarse elongated structures. Finally, the dispersed PA phase featured solely coarse elongated domains when the PLA content was decreased to $50 \mathrm{wt} \%$.

Significant morphological changes occurred with the modification of the PLA flow behaviour. In the PLA $_{\text {REx }}$ composition range $90-80 \mathrm{wt} \%$, the PA dispersed droplets were much finer and more homogeneously dispersed than PLA-based bio-blends, as shown in Figure 4. Increasing the PA content also increased the weight-average particle diameter but to a much lesser extend as compared to their PLA counterpart. $\bar{d}_{\mathrm{w}}$ increased from initially 0.19 to $0.24 \mu \mathrm{m}$. To the best of our knowledge similar size of the PA
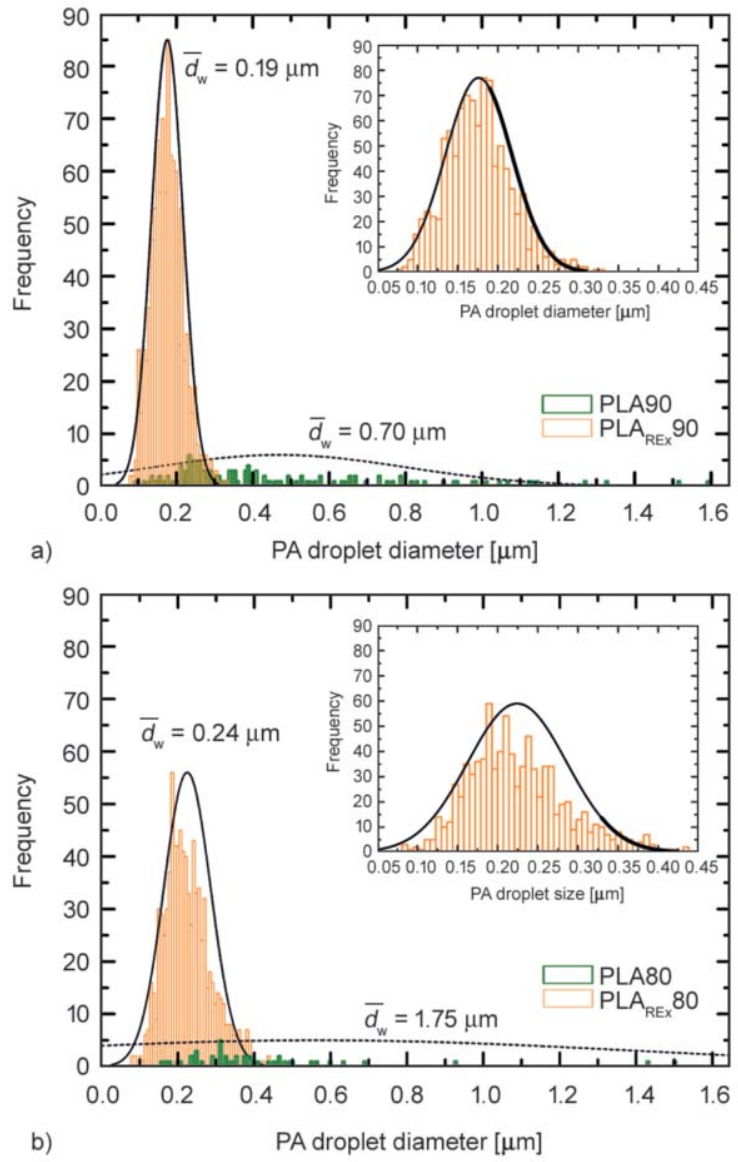

Figure 4. Quantitative analyses of the PA weight-average particle diameter, $\bar{d}_{\mathrm{w}}$, in PLA and PLA $A_{\mathrm{REx}}$ composition a) $90 / 10$, b) $80 / 20$. Inserts show a detailed view of the PA particle diameter distribution for PLA $_{\text {REx }}$-based bio-blends.

disperse phase in PLA/PA systems has only been reported by Kakroodi et al. [2] for thin PA6 microfibrils in a two-step hot stretching process. In this study, the observed morphological improvement must be primarily attributed to the higher shear viscosity of the PLA $A_{R E x}$ matrix during compounding. That is, the enhanced $\eta_{P L A_{R E x}}$ possibly increased the local shear field applied to the initial coarse PA domains; thus enabling further PA droplet breakup and minimizing coalescence during mixing. Similar observations have been already reported by Lee et al. [9] regarding the evolution of blend morphology in different blend systems.

When the PA content was $30 \mathrm{wt} \%$ both droplet and elongated PA domains coexisted. The morphology transition to co-continuous was completed when the PA content was further increased to $40 \mathrm{wt} \%$. Irregularly shaped PA domains interpenetrated the PLA $_{\text {REx }}$ major phase in the PLA $\mathrm{REx}_{60} 6$ formulation. These observations are in agreement with the initial rheological predictions. Finally, elongated PLAREx 


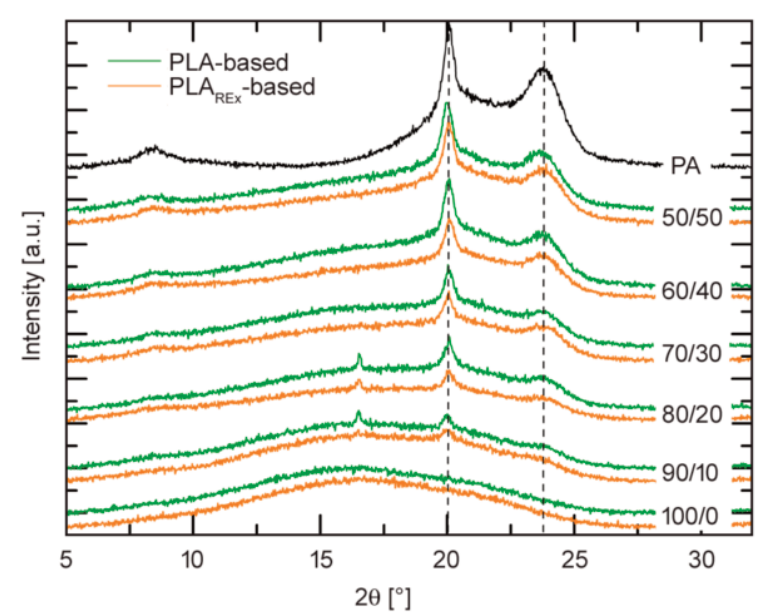

Figure 5. WAXS profiles for all manufactured materials.

domains in PA were revealed for the PLA $\mathrm{REx}_{50}$ sample.

It is well known that mechanical performances of polymer systems are highly dependent on the crystallinity induced during manufacturing. On this basis, WAXS experiments were performed on all the compression moulded samples. WAXS patterns recorded

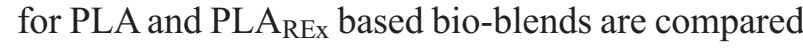
in Figure 5. PLA and PLA $A_{\text {REx }}$ intensity profiles do not display any crystalline reflections, which indicate that both processed neat samples were amorphous under the processing conditions used in this study. These observations are in agreement with the slow kinetics of crystallization exhibited by both materials, as already reported elsewhere $[29,30]$. Nevertheless, a small diffraction peak at $2 \theta=16.4^{\circ}$ corresponding to PLA $\alpha$ form crystallinity [2] can be seen for the $90 / 10$ and the $80 / 20$ blends, being more prominent in the case of PLA-based blends. This indicates that the presence of small amounts (10-20 wt \%) of PA10.10 acted as a heterogeneous nucleating agent and formed a small PLA crystal fraction in these blends. Indeed, Kakroodi et al. [2] showed that micron- and sub-micron-sized PA domains dispersed in PLA matrix increased the PLA crystallization rate. Nevertheless, no such effect was seen for higher PA contents. In contrast, the monoclinic $\alpha$ crystal phase of neat PA samples was present through the peaks at about $2 \theta=20.5$ and $23.5^{\circ}$ [31]. Analogously, PLA

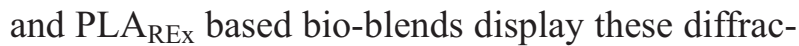
tion peaks corresponding to the PA crystal form.

The mechanical properties of polymer blends further depend on the interfacial adhesion between the polymer phases. The contact angle of polymers mainly depends on their chemical structure and surface roughness and is characteristic for their hydrophilic properties and thus their wettability of other polymers $[13,14]$.

The results of the surface contact angles and the surface free energy calculations of PA, PLA and PLA $_{\text {REx }}$ are shown in Figure 6 and Table 3. Comparing PLA and PLA $A_{R E x}$, the water contact angle dropped from 75 to $63^{\circ}$, suggesting a more hydrophilic nature of PLA $A_{\text {REx }}$. The surface energy of PLA calculated according to the Owens-Wendt method was $42.6 \mathrm{~mJ} / \mathrm{m}^{2}$ which agreed well with published values from other researchers [14, 32]. The reactive extrusion of PLA and multifunctional epoxide reactive agent (i.e. $P_{\text {PLA }}$ REx increased the surface energy to $51.5 \mathrm{~mJ} / \mathrm{m}^{2}$. This enhancement was due to the large increase in the dispersive component while the increase in the polar component was not significant. The increased surface energy of PLA REx resulted in less interfacial
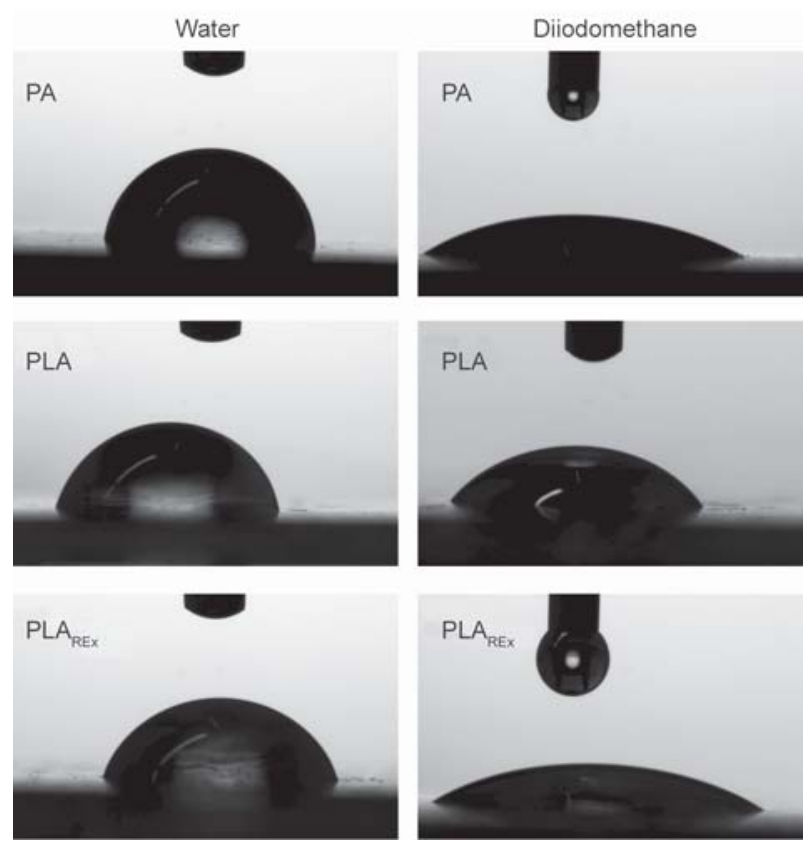

Figure 6. Water and diiodomethane contact angles of PA, PLA and PLAREx.

Table 3. Average contact angles and surface free energies of PA, PLA and PLA REx.

\begin{tabular}{|l|c|c|c|c|c|}
\hline \multicolumn{1}{|c|}{ Sample } & $\begin{array}{c}\text { Contact angle } \boldsymbol{\theta} \\
\text { water }\left[{ }^{\circ} \mathbf{}\right]\end{array}$ & $\begin{array}{c}\text { Contact angle } \boldsymbol{\theta} \\
\text { diiodomethane }\left[{ }^{\circ} \mathbf{}\right]\end{array}$ & $\begin{array}{c}\text { Surface energy } \\
{\left[\mathbf{m} \mathbf{J} / \mathbf{m}^{\mathbf{2}}\right]}\end{array}$ & $\begin{array}{c}\text { Dispersive component } \\
{\left[\mathbf{m J} / \mathbf{m}^{\mathbf{2}}\right]}\end{array}$ & $\begin{array}{c}\text { Polar component } \\
{\left[\mathbf{m J} / \mathbf{m}^{\mathbf{2}}\right]}\end{array}$ \\
\hline PA & $86 \pm 2$ & $27 \pm 2$ & 46.4 & 45.4 & 1.1 \\
\hline PLA & $75 \pm 2$ & $48 \pm 3$ & 42.6 & 35.4 & 7.2 \\
\hline PLA $_{\mathrm{REx}}$ & $63 \pm 3$ & $30 \pm 3$ & 51.5 & 44.2 & 7.3 \\
\hline
\end{tabular}


tension during blending with PA and consequently led to a size reduction of the dispersed phase and a better interfacial adhesion as compared to PLA blends.

Representative tensile engineering stress-strain curves for both types of bio-blends are shown in Figure 7. The tensile properties are compiled in Table 4 and Figure 8. Both PLA and PLA REx $_{\text {exhibited similar prop- }}$ erties, namely a high stiffness and strength coupled with brittleness (i.e. low strain at break). For both PLA

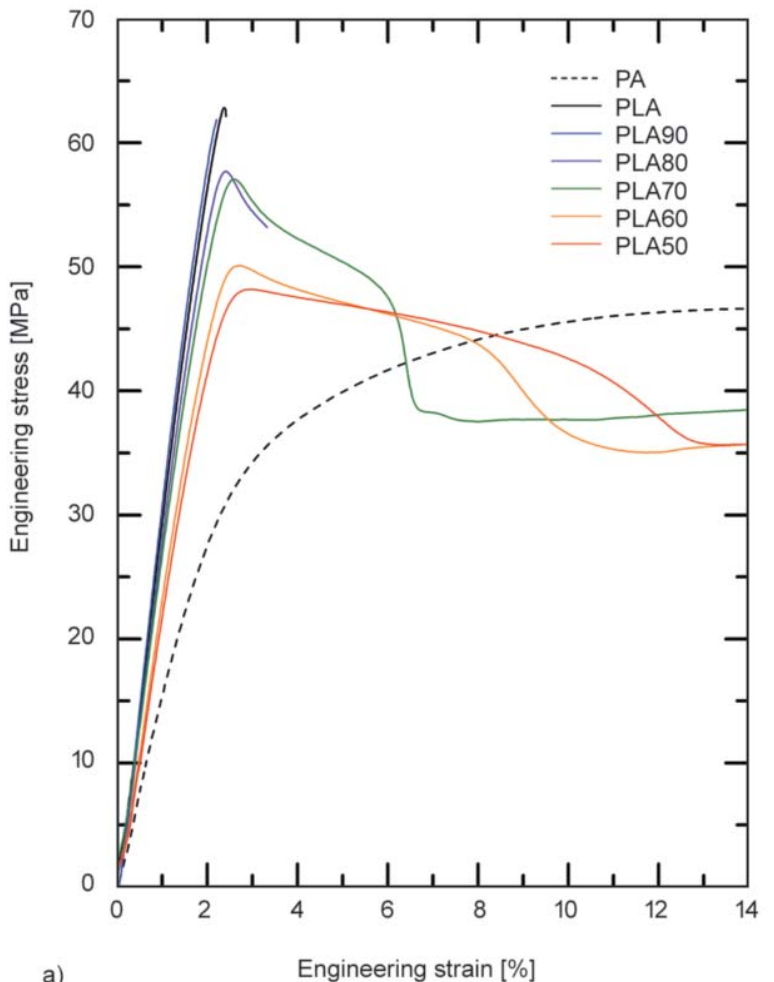

and PLA $A_{\text {REx }}$ blends the stiffness and strength decreased gradually from around 2.3 to $1.3 \mathrm{GPa}$ and from 63 to $48 \mathrm{MPa}$, respectively, when the PA content increased. The strain at break of the PLA $\mathrm{REx}^{-}$ based bio-blends increased also significantly with increasing PA content. However, the 90/10 blends showed a higher modulus as compared to their corresponding PLA matrix. Recall that according to WAXS results this blend exhibited a small PLA crystal

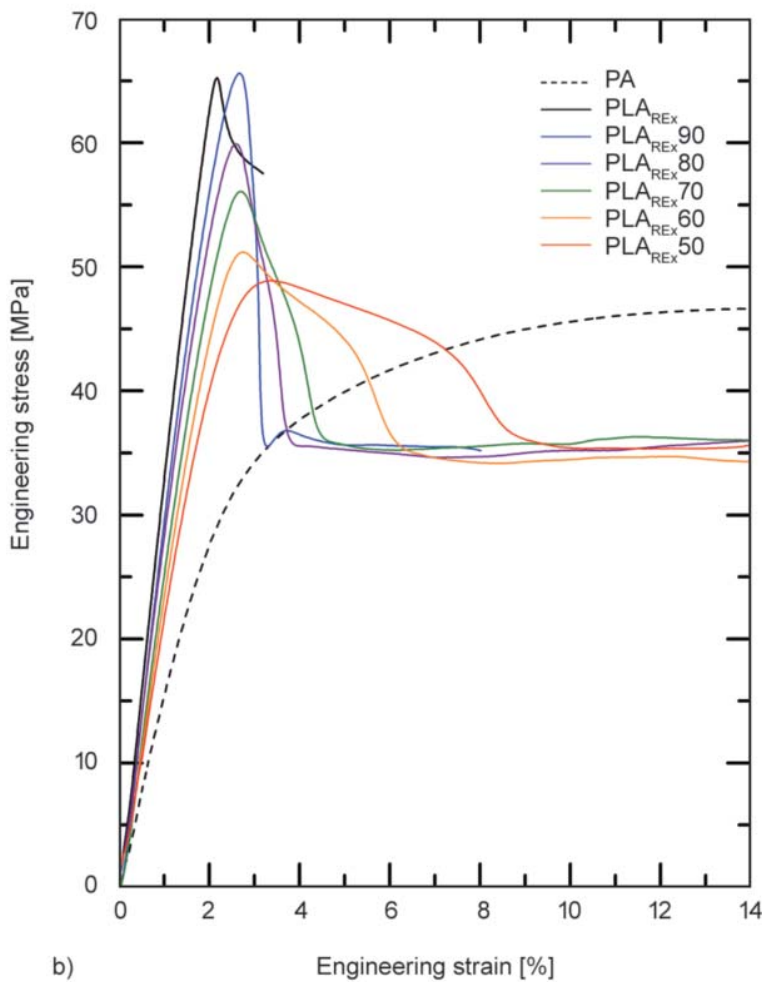

Figure 7. Typical uniaxial tensile engineering stress-strain curves for PLA (a) and PLA REx (b) based bio-blends.

Table 4. Uniaxial tensile properties, tensile impact strength $\mathrm{a}_{\mathrm{tU}}$ and PA weight-average particle diameter $\bar{d}_{\mathrm{w}}$.

\begin{tabular}{|c|c|c|c|c|c|}
\hline Sample & $\begin{array}{c}E \\
{[\mathbf{G P a}]}\end{array}$ & $\begin{array}{c}\sigma_{\mathrm{m}} \\
{[\mathrm{MPa}]}\end{array}$ & $\begin{array}{c}\varepsilon_{\mathrm{b}} \\
{[\%]}\end{array}$ & $\begin{array}{c}a_{\mathrm{tU}} \\
{\left[\mathbf{k J} \cdot \mathbf{m}^{-2}\right]}\end{array}$ & $\begin{array}{c}\bar{d}_{\mathrm{w}} \\
{\left[\mu_{\mathrm{m}}\right]^{*}}\end{array}$ \\
\hline PLA & $2.3 \pm 0.1$ & $63 \pm 1$ & $2.5 \pm 0.3$ & $102 \pm 20$ & $\mathrm{n} / \mathrm{a}$ \\
\hline PLA $_{\text {REx }}$ & $2.6 \pm 0.2$ & $64 \pm 1$ & $3.2 \pm 0.1$ & $106 \pm 11$ & $\mathrm{n} / \mathrm{a}$ \\
\hline PA & $1.5 \pm 0.1$ & $46 \pm 1$ & $155 \pm 27.0$ & $459 \pm 65$ & $\mathrm{n} / \mathrm{a}$ \\
\hline \multicolumn{6}{|c|}{ PLA-based bio-blends } \\
\hline PLA90 & $2.9 \pm 0.2$ & $61 \pm 2$ & $2.2 \pm 0.1$ & $68 \pm 5$ & 0.702 \\
\hline PLA80 & $1.8 \pm 0.1$ & $58 \pm 2$ & $3.6 \pm 0.8$ & $111 \pm 16$ & 1.752 \\
\hline PLA70 & $1.8 \pm 0.1$ & $57 \pm 1$ & $28 \pm 5.0$ & $145 \pm 12$ & 2.551 \\
\hline PLA60 & $1.4 \pm 0.2$ & $50 \pm 1$ & $142 \pm 39.0$ & $221 \pm 39$ & $\mathrm{n} / \mathrm{a}$ \\
\hline PLA50 & $1.3 \pm 0.1$ & $48 \pm 1$ & $117 \pm 60.0$ & $221 \pm 55$ & $\mathrm{n} / \mathrm{a}$ \\
\hline \multicolumn{6}{|c|}{ PLA $_{\text {REx }}$-based bio-blends } \\
\hline PLA $_{\text {REx }} 90$ & $2.7 \pm 0.1$ & $66 \pm 1$ & $18 \pm 12.0$ & $98 \pm 23$ & 0.186 \\
\hline $\mathrm{PLA}_{\mathrm{REX}} 80$ & $2.2 \pm 0.1$ & $60 \pm 1$ & $166 \pm 9.0$ & $126 \pm 6$ & 0.241 \\
\hline $\mathrm{PLA}_{\mathrm{REx}} 70$ & $2.0 \pm 0.2$ & $58 \pm 1$ & $144 \pm 15.0$ & $174 \pm 27$ & $\mathrm{n} / \mathrm{a}$ \\
\hline $\mathrm{PLA}_{\mathrm{REx}} 60$ & $1.4 \pm 0.2$ & $51 \pm 1$ & $162 \pm 32.0$ & $280 \pm 43$ & $\mathrm{n} / \mathrm{a}$ \\
\hline $\mathrm{PLA}_{\mathrm{REx}} 50$ & $1.3 \pm 0.1$ & $49 \pm 1$ & $173 \pm 26.0$ & $333 \pm 39$ & $\mathrm{n} / \mathrm{a}$ \\
\hline
\end{tabular}

${ }^{*}$ The weight-average particle diameters were only calculated for formulations exhibiting near-spherical PA droplets. 


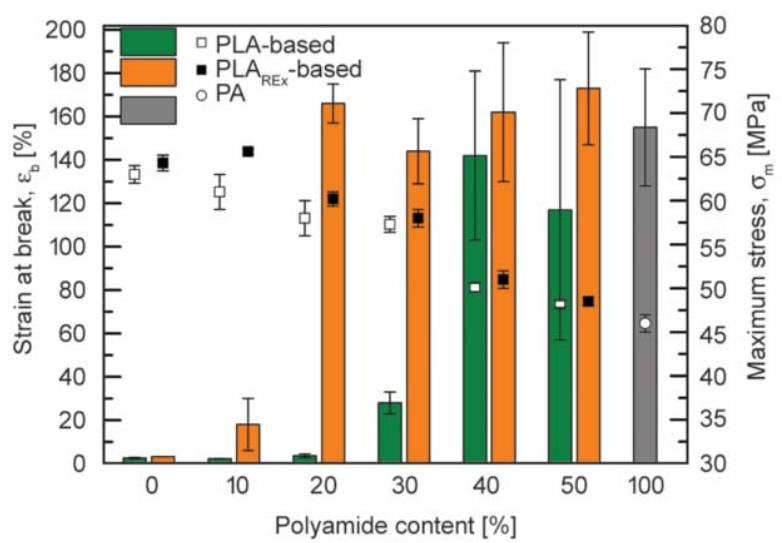

Figure 8. Effect of the PA content on the strain at break (column bar) and maximum stress (scatter) for both types of bio-blends.

fraction which was absent in blends with higher PA content. This PLA crystal fraction might account for the relatively higher stiffness of this blend.

Regarding the failure strain, a semi-ductile behaviour was observed for the $\operatorname{PLA}_{\mathrm{REx}} 90$ formulation and
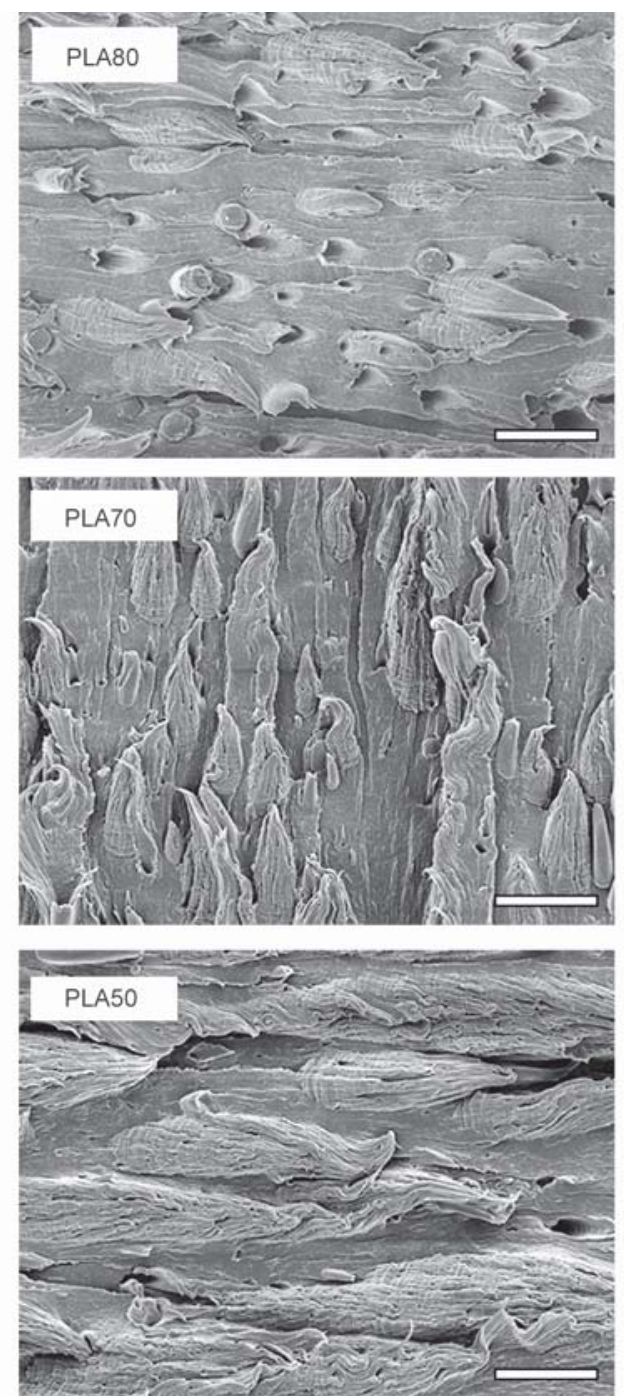

strain at break values well above $100 \%$ were measured for higher PA contents. On the other hand, the PLA-based bio-blends did not show this behaviour. The addition of 10 or $20 \mathrm{wt} \%$ of PA did not affect the PLA brittleness. A semi-ductile behaviour was observed for the PLA70 blend and strain at break values were above $100 \%$ for PA contents of $40 \mathrm{wt} \%$ or higher. The relatively large scatter in the failure strain data of PLA-based blends with high PA content is due to the unstable necking of the tensile specimens. This was ascribed to the relatively coarser microstructure featuring large PA particles which led to premature failure. To sum up, an apparent brittleto-ductile transition was observed when the PA content in PLA-based bio-blends was $30 \mathrm{wt} \%$. In PLA RExbased blends this transition was achieved with only $10 \mathrm{wt} \%$ of PA. In Figure 9, the SEM morphologies of the fracture surfaces of tensile specimens reflect well this brittle-to ductile transition. For instance, the morphology of the PLA 80 bio-blend exhibits a quite
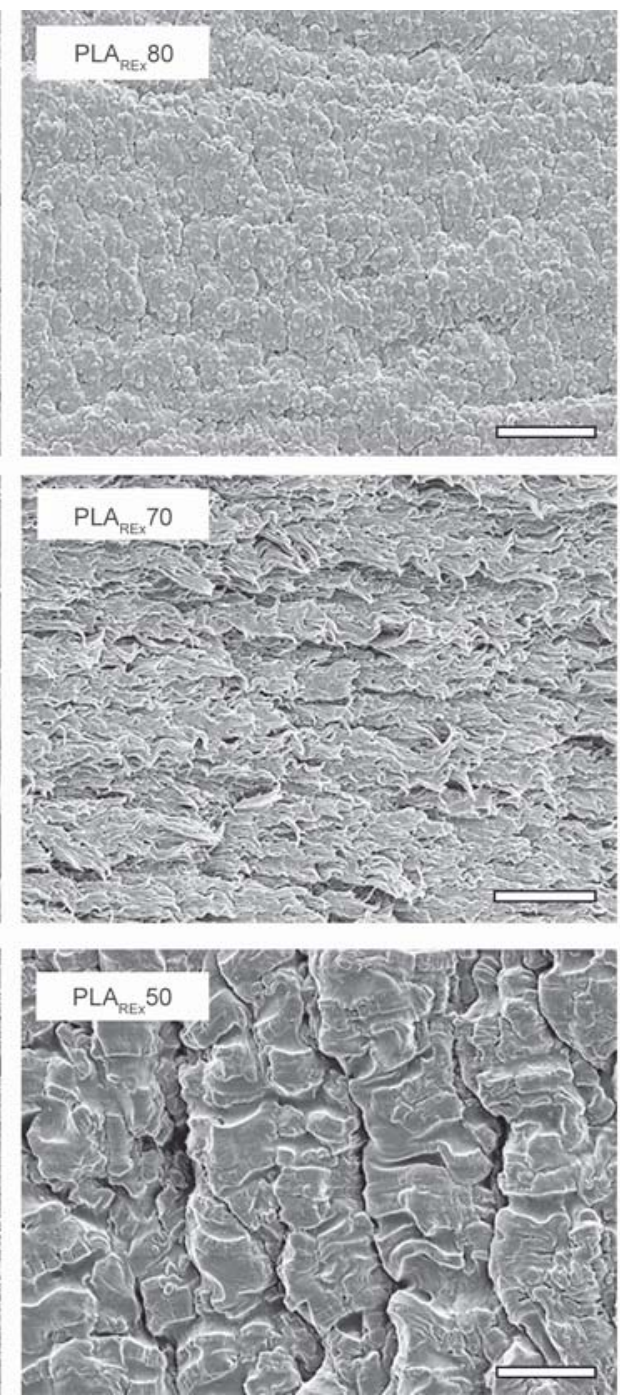

Figure 9. SEM micrographs $(\times 5000)$ of the tensile fractured surfaces of PLA- and PLA $A_{\text {REx }}$-based bio-blends. Scale bars $=4 \mu \mathrm{m}$. 
smooth fracture surface together with the tearing and decohesion of PA particles. This suggests a brittle fracture and indeed the observed strain at break was only about $4 \%$. In contrast, the fractured surface of the PLA $\mathrm{REx}_{\mathrm{R}} 80$ bio-blend does not display any particle decohesion mechanism. Under tensile loading the smaller and homogeneously dispersed PA droplets allow a significant release of the triaxial stress state in the matrix, thus allowing the specimen to undergo shear yielding.

The SEM images of the PLA70 and PLA50 bioblend featured a typical fibrillated structure originated from the ductile tearing of the larger PA particles. It is not surprising that a certain extend of fibril debonding can equally be observed due to the poor interfacial adhesion between both polymers. These observations confirm the observed semi-ductile and/or ductile behaviour of these blends. In contrast, stretched fibrils appeared to be more uniform for PLA $_{\text {REx }} 70$ based bio-blend due to the finer dispersion of the initial PA droplets combined with the presence of microfibrils, thus greatly enhancing the toughness of this formulation. Finally, PLA $\mathrm{REx} 50$ bio-blends exhibited the typical fracture surface features of phase inverted blends.

The PA weight-average particle diameters of the different PLA and PLA $\mathrm{REx}$-based bio-blends featuring only near-spherical PA droplets were determined from the SEM morphologies and are compiled in Table 3. It is apparent that PLA-based blends exhibited relatively large PA particle diameters $>1 \mu \mathrm{m}$ while the particle diameters in PLA REx $_{\text {-based blends }}$ were around ten times smaller. The relatively finer microstructure of PLA $A_{R E x}$ together with its enhanced interfacial adhesion resulted in a ductile behaviour with failure strains well above $100 \%$.

The toughening effect of the dispersed PA on the PLA and PLA $A_{\text {REx }}$ matrices was also observed in tensile-impact tests (c.f. Table 4). Figure 10 depicts the tensile-impact strength $a_{\mathrm{tU}}$ as a function of PA con-

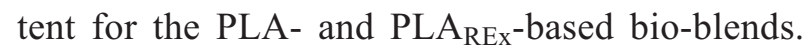
Contrary to what was observed in quasi-static uniaxial tensile tests, the tensile-impact strength increased only marginally and no clear brittle-to-ductile transition was found. The tensile-impact strength of both matrices was not markedly affected up to a PA content of $20 \mathrm{wt} \%$ and then gradually increased for higher PA contents due to the ductile behaviour of the increasingly PA secondary phase. This improvement

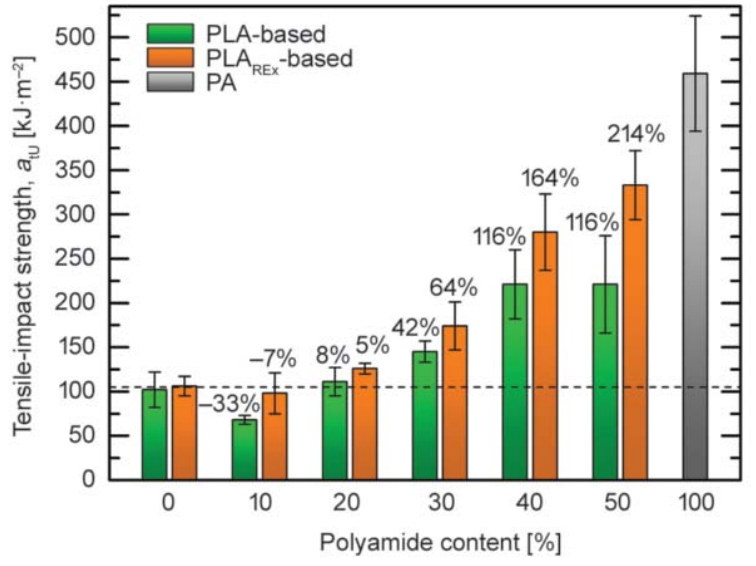

Figure 10. Tensile-impact strength for PLA and PLA $\mathrm{REx}^{-}$ based bio-blends.

was always more pronounced for the PLA $A_{R E x}$-based bio-blends due to the morphological improvements as observed in Figure 3.

\section{Conclusions}

This work shows that PLA/PA bio-blends have the potential to overcome the inherent brittleness of PLA. However, $30 \mathrm{wt} \%$ of PA was needed to achieve a brittle-to-ductile transition and a co-continuous morphology was found at $58 \mathrm{wt} \%$ of PA due to the immiscible nature of the blend. Unfortunately, increasing the PA fraction significantly reduced the PLA stiffness and strength and also increased the size of the dispersed PA phase.

On the other hand, the initial improvement of the PLA rheological behaviour through reactive extrusion yielded a finer and more homogeneous microstructure and apparently a better interfacial adhesion since the PA dispersed phase was covered with matrix. Consequently, the mechanical properties of the $\mathrm{PLA}_{\mathrm{REx}} / \mathrm{PA}$ bio-blends were enhanced at much lower PA contents. Under uniaxial tensile conditions, the brittle-to-ductile transition could be achieved with only $10 \mathrm{wt} \%$ and co-continuity was observed already at $44 \mathrm{wt} \%$ of PA. These findings may help to establish PLA REX $_{\text {PA bio-blends, such as the } 80 / 20}$ formulation, with high PLA fractions and good toughness without significantly sacrificing stiffness and strength.

\section{Acknowledgements}

The authors acknowledge the financial support from the Spanish Ministry of Economy and Competitiveness through the Project MAT2016-80045-R (AEI/FEDER,UE). 


\section{References}

[1] Spinella S., Cai J., Samuel C., Zhu J., McCallum S. A., Habibi Y., Raquez J-M., Dubois P., Gross R. A.: Polylactide/poly( $\omega$-hydroxytetradecanoic acid) reactive blending: A green renewable approach to improving polylactide properties. Biomacromolecules, 16, 1818-1826 (2015).

https://doi.org/10.1021/acs.biomac.5b00394

[2] Kakroodi A. R., Kazemi Y., Ding W., Ameli A., Park C. B.: Poly(lactic acid)-based in situ microfibrillar composites with enhanced crystallization kinetics, mechanical properties, rheological behavior, and foaming ability. Biomacromolecules, 16, 3925-3935 (2015). https://doi.org/10.1021/acs.biomac.5b01253

[3] Pai F-C., Lai S-M., Chu H-H.: Characterization and properties of reactive poly(lactic acid)/polyamide 610 biomass blends. Journal of Applied Polymer Science, 130, 2563-2571 (2013).

https://doi.org/10.1002/app.39473

[4] Stoclet G., Seguela R., Lefebvre J-M.: Morphology, thermal behavior and mechanical properties of binary blends of compatible biosourced polymers: Polylactide/polyamide-11. Polymer, 52, 1417-1425 (2011). https://doi.org/10.1016/j.polymer.2011.02.002

[5] Rashmi B. J., Prashantha K., Lacrampe M-F., Krawczak P.: Toughening of poly(lactic acid) without sacrificing stiffness and strength by melt-blending with polyamide-11 and selective localization of halloysite nanotubes. Express Polymer Letters, 9, 721-735 (2015). https://doi.org/10.3144/expresspolymlett.2015.67

[6] Nuzzo A., Coiai S., Carroccio S. C., Dintcheva N. T., Gambarotti C., Filippone G.: Heat-resistant fully biobased nanocomposite blends based on poly(lactic acid). Macromolecular Materials and Engineering, 299, 3140 (2014).

https://doi.org/10.1002/mame.201300051

[7] Patel R., Ruehle D. A., Dorgan J. R., Halley P., Martin D.: Biorenewable blends of polyamide-11 and polylactide. Polymer Engineering and Science, 54, 1523-1532 (2014). https://doi.org/10.1002/pen.23692

[8] Palacios J. K., Sangroniz A., Eguiazabal J. I., Etxeberria A., Müller A. J.: Tailoring the properties of PP/PA6 nanostructured blends by the addition of nanosilica and compatibilizer agents. European Polymer Journal, 85, 532 552 (2016).

https://doi.org/10.1016/j.eurpolymj.2016.11.010

[9] Lee J. K., Han C. D.: Evolution of polymer blend morphology during compounding in an internal mixer. Polymer, 40, 6277-6296 (1999).

https://doi.org/10.1016/S0032-3861(99)00022-1

[10] Burch H. E., Scott C. E.: Effect of viscosity ratio on structure evolution in miscible polymer blends. Polymer, 42, 7313-7325 (2001).

https://doi.org/10.1016/S0032-3861(01)00240-3
[11] Jana S. C., Sau M.: Effects of viscosity ratio and composition on development of morphology in chaotic mixing of polymers. Polymer, 45, 1665-1678 (2004).

https://doi.org/10.1016/j.polymer.2003.12.047

[12] Inkinen S., Hakkarainen M., Albertsson A-C., Södergård A.: From lactic acid to poly(lactic acid) (PLA): characterization and analysis of PLA and its precursors. Biomacromolecules, 12, 523-532 (2011).

https://doi.org/10.1021/Bm101302t

[13] Owens D. K., Wendt R.: Estimation of the surface free energy of polymers. Journal of Applied Polymer Science, 13, 1741-1747 (1969). https://doi.org/10.1002/app.1969.070130815

[14] Jordá-Vilaplana A., Fombuena V., García-García D., Samper M., Sánchez-Nácher L.: Surface modification of polylactic acid (PLA) by air atmospheric plasma treatment. European Polymer Journal, 58, 23-33 (2014). https://doi.org/10.1016/j.eurpolymj.2014.06.002

[15] Rudawska A., Jacniacka E.: Analysis for determining surface free energy uncertainty by the Owen-Wendt method. International Journal of Adhesion and Adhesives, 29, 451-457 (2009). https://doi.org/10.1016/j.ijadhadh.2008.09.008

[16] Cox W. P., Merz E. H.: Correlation of dynamic and steady flow viscosities. Journal of Polymer Science, 28, 619-622 (1958). https://doi.org/10.1002/pol.1958.1202811812

[17] Skrovanek D. J., Painter P. C., Coleman M. M.: Hydrogen bonding in polymers. 2 . Infrared temperature studies of nylon 11. Macromolecules, 19, 699-705 (1986). https://doi.org/10.1021/ma00157a037

[18] Krache R., Benachour D., Pötschke P.: Binary and ternary blends of polyethylene, polypropylene, and polyamide 6,6: The effect of compatibilization on the morphology and rheology. Journal of Applied Polymer Science, 94, 1976-1985 (2004).

https://doi.org/10.1002/app.21098

[19] Shin B. Y., Jo G. S., Kang K. S., Lee T. J., Kim B. S., Lee S. I., Song J. S.: Morphology and rheology on the blends of PLA/CMPS. Macromolecular Research, 15, 291-301 (2007).

https://doi.org/10.1007/BF03218790

[20] Lyngaae Jørgensen J., Rasmussen K. L., Chtcherbakova E., Utracki L.: Flow induced deformation of dualphase continuity in polymer blends and alloys. Part I. Polymer Engineering and Science, 39, 1060-1071 (1999). https://doi.org/10.1002/pen.11494

[21] Mekhilef N., Verhoogt H.: Phase inversion and dualphase continuity in polymer blends: theoretical predictions and experimental results. Polymer, 37, 4069-4077 (1996). https://doi.org/10.1016/0032-3861(96)00254-6

[22] Andradi L., Hellmann G.: Morphologies of mechanically mixed amorphous blends before and after annealing. Polymer Engineering and Science, 35, 693-702 (1995).

https://doi.org/10.1002/pen.760350809 
[23] Hietaoja P. T., Holsti Miettinen R. M., Seppälä J. V., Ikkala O. T.: The effect of viscosity ratio on the phase inversion of polyamide 66/polypropylene blends. Journal of Applied Polymer Science, 54, 1613-1623 (1994). https://doi.org/10.1002/app.1994.070541104

[24] Utracki L.: On the viscosity concentration dependence of immiscible polymer blends. Journal of Rheology, 35, 1615-1637 (1991).

https://doi.org/10.1122/1.550248

[25] Steinmann S., Gronski W., Friedrich C.: Cocontinuous polymer blends: Influence of viscosity and elasticity ratios of the constituent polymers on phase inversion. Polymer, 42, 6619-6629 (2001).

https://doi.org/10.1016/S0032-3861(01)00100-8

[26] Pötschke P., Paul D.: Formation of co-continuous structures in melt-mixed immiscible polymer blends. Journal of Macromolecular Science Part C: Polymer Reviews, 43, 87-141 (2003).

https://doi.org/10.1081/MC-120018022

[27] Bousmina M., Ait-Kadi A., Faisant J.: Determination of shear rate and viscosity from batch mixer data. Journal of Rheology, 43, 415-433 (1999).

https://doi.org/10.1122/1.551044

[28] Cailloux J., Santana O. O., Franco-Urquiza E., Bou J. J., Carrasco F., Gámez-Pérez J., Maspoch M. L.: Sheets of branched poly(lactic acid) obtained by one step reactive extrusion calendering process: Melt rheology analysis. Express Polymer Letters, 7, 304-318 (2013). https://doi.org/10.3144/expresspolymlett.2013.27
[29] Hakim R., Cailloux J., Santana O., Bou J., Sánchez-Soto M., Odent J., Raquez J., Dubois P., Carrasco F., Maspoch M. L.: PLA $/ \mathrm{SiO}_{2}$ composites: Influence of the filler modifications on the morphology, crystallization behavior, and mechanical properties. Journal of Applied Polymer Science, 134, 45367/1-45367/12 (2017).

https://doi.org/10.1002/app.45367

[30] Pan P., Kai W., Zhu B., Dong T., Inoue Y.: Polymorphous crystallization and multiple melting behavior of poly(L-lactide): Molecular weight dependence. Macromolecules, 40, 6898-6905 (2007).

https://doi.org/10.1021/Ma071258d

[31] Guo H., Wang J., Zhou C., Zhang W., Wang Z., Xu B., Li J., Shang Y., de Claville Christiansen J., Yu D.: Direct investigations of deformation and yield induced structure transitions in polyamide 6 below glass transition temperature with WAXS and SAXS. Polymer, 70, 109-117 (2015).

https://doi.org/10.1016/j.polymer.2015.06.013

[32] Rigoussen A., Verge P., Raquez J-M., Habibi Y., Dubois P.: In-depth investigation on the effect and role of cardanol in the compatibilization of PLA/ABS immiscible blends by reactive extrusion. European Polymer Journal, 93, 272-283 (2017).

https://doi.org/10.1016/j.eurpolymj.2017.06.004 